\title{
Sludge conditioning of oil emulsion wastewater process by heat treatment using low temperatures in Siberia
}

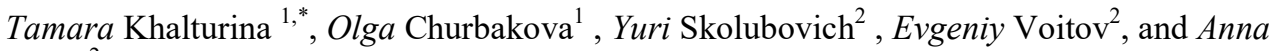 \\ Tsyba $^{2}$ \\ ${ }^{1}$ Siberian Federal University, 660041, 23 (A), Svobodny Ave., Krasnoyarsk, Russia \\ ${ }^{2}$ Novosibirsk State University of Architecture and Civil Engineering (Sibstrin), 630008, 113, \\ Leningradskaya st., Novosibirsk, Russia
}

\begin{abstract}
The relevance of this study is due to the problem's solution of preventing negative impact on the environment during the industrial waste disposal, as well as insufficient high-performance technologies for the treatment of sewage sludge in Siberian severe climatic conditions. Experimental studies of the properties, composition and structure of oilemulsion wastewater sludge using $\mathrm{x}$-ray phase and thermogravimetric analysis showed that the natural sludge, characterized by high humidity and a high value of specific filtration resistance is in an amorphous state The results of experimental studies on the conditioning process of oil emulsion wastewater sludge by heat treatment using low temperatures in the natural climatic conditions of Siberia are obtained. They can be used to develop effective technologies for processing and utilizing precipitation, which allows solving the problems of reducing the industrial impact on the environment
\end{abstract}

\section{Introduction}

The solution to the problem of preventing negative impacts during the process of reducing waste from industrial enterprises is relevant, in accordance with the Federal Law "On Environmental Protection", dated January 10, 2002. (No. 7-FZ of the Russian Federation in the field of water supply and sanitation). Currently, highly efficient processing technologies have not been sufficiently developed to intensify dehydration of sewage sludge from industrial enterprises in the severe climatic conditions of Siberia.

It is known that the use of cryogenesis method during freezing process under natural conditions and melting makes it possible to increase the precipitations' water loss [1,2], storage facilities are used for, where the sewage sludge does not freeze due to the good thermal insulation properties of snow and ice at a considerable depth.

The use of storages or silt sites for freezing and melting sludge is characterized by disadvantages such as significant areas occupation and the inability to regulate the

* Corresponding author: michmacha@mail.ru 
cryogenic treatment process, taking into account the influence on the properties of precipitation during cryogenesis of air temperature and wind speed $[2,3]$.

The purpose of these studies was to study cryogenesis within regulating the process of freezing sewage sludge from metalworking enterprises in the natural climatic conditions of Siberia.

\section{Materials and research methods}

In order to experimentally study the composition and structure of the precipitate, an X-ray phase analysis was performed with the use of D8-ADVANCE diffractometer of the German company Bruker-ASX, and a thermogravimetric analysis with the use of STA 449F1 device of the German company NETZSCH also, in the range of 30/200 K/ $\mathrm{min} / 1000$.

\section{The results of the study}

Diffraction pattern of natural sediment of oil-emulsion wastewater was obtained during $\mathrm{x}$ ray phase analysis conducting with a use of D8-ADVANCE diffractometer of the German company Bruker-ASX, which was shown in Figure 1.

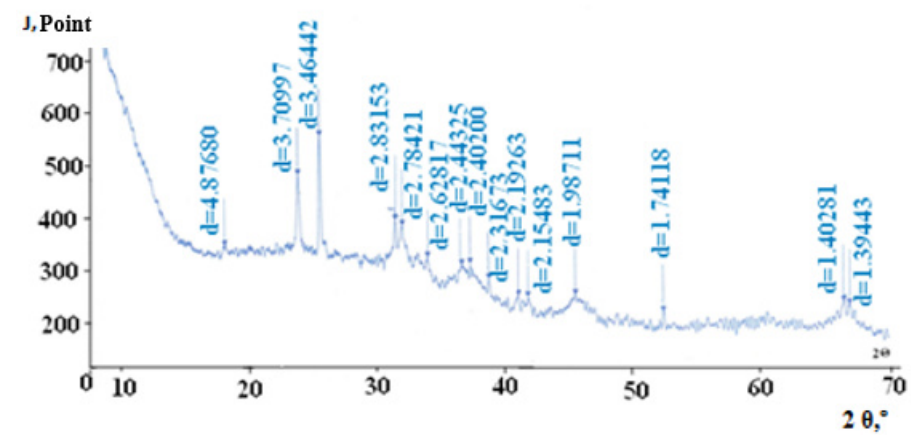

Fig 1. Diffraction pattern of a natural sediment of oil emulsion wastewater.

The diffraction pattern shows, the precipitate is mainly represented by polymer modifications of alumina, i.e., gibbsite, bayerite and boehmite, as indicated by lines with $\mathrm{d}=3.70, \mathrm{~d}=3.46, \mathrm{~d}=2.62, \mathrm{~d}=2.40, \mathrm{~d}=1.40$. The lines at $\mathrm{d}=2.83 ; \mathrm{d}=1.98$ are typical for calcium compounds $\mathrm{CaCO}_{3}, \mathrm{CaSO}_{4}$, since the $\mathrm{pH}$ was adjusted to 7.5 with the addition of a suspension of lime milk for subsequent separation of the precipitate after wastewater coagulation treatment [4].

X-ray phase analysis showed that lines with $\mathrm{d}=4.87, \mathrm{~d}=1.98$ correspond to quartzite $\mathrm{SiO}_{2}$. The diffraction pattern indicates that the degree of the precipitate ordering is low; the precipitate is in an amorphous form of a coagulated colloid of aluminum hydroxide with adsorbed particles of emulsified oil products and suspended solids. Thermo gravimetric analysis of the precipitate was also performed with the use of STA 449F1 device of the German company NETZSCH in the range of $30 / 200 \mathrm{~K} / \mathrm{min} / 1000$, in the DSC- TG mode, where DSC is differential scanning calorimetry, TG is the mass change curve, $\%$.

The thermogram shows three endo-effects on the DSC curve: two endo-effects are associated with dehydration at $\mathrm{t}=110.4{ }^{0} \mathrm{C}$ и $\mathrm{t}=381.5^{\circ} \mathrm{C}$, and at $\mathrm{t}=735.9^{\circ} \mathrm{C}, \mathrm{CaCO}_{3}$ decomposes. Exo effects occur at $\mathrm{t}=325.0^{\circ} \mathrm{C}$, which is explained by the polymorphic conversion of aluminum oxyhydrate forms, and the double effect at $\mathrm{t}=480.0^{\circ} \mathrm{C}$ and $\mathrm{t}=656.0^{\circ} \mathrm{C}$ is associated with the burnout of oils. The residual weight of the sediment sample is $40.32 \%$. 
The properties of the natural sediment of oil emulsion wastewater, presented in table 1, were studied.

Table 1. Sediment Properties

\begin{tabular}{|c|c|c|c|c|l|}
\hline $\begin{array}{l}\text { Type of } \\
\text { sedimen } \\
\text { t }\end{array}$ & $\begin{array}{l}\text { Densit } \\
\mathbf{y}, \mathbf{g} / \\
\mathbf{s m 3}\end{array}$ & $\begin{array}{l}\text { Humidity, } \\
\mathbf{\%}\end{array}$ & $\begin{array}{l}\text { The dry residue } \\
\text { after drying } \\
\text { vania,\% }\end{array}$ & Oil content,\% & $\begin{array}{l}\text { Filter } \\
\text { resistivity, } \\
\text { cm/g }\end{array}$ \\
\hline $\begin{array}{c}\text { Mes } \\
\text { sediment }\end{array}$ & 1.0 & 99 & 48.6 & 51.4 & $690 * 10^{10}$ \\
\hline
\end{tabular}

As it follows from table 1, the precipitate is characterized by high humidity and a high value of specific filtration resistance.

Determination of the composition and the precipitate structure after freezing and thawing to develop a technology for its disposal was also performed using thermo gravimetric analysis on a STA 449F1 device of the German company NETZSCH in the range of $30 / 200 \mathrm{~K} / \mathrm{min} / 1000$.

An analysis of DSC curves shows that differences are observed in peak widths and maximum temperature values on the samples of the initial precipitate (Fig. 2) and the precipitate after cryogenic treatment (Fig. 3): $\mathrm{t}=123.1^{\circ} \mathrm{C}$ and $\mathrm{t}=115.4^{\circ} \mathrm{C}$ are endo effects, explained by dehydration, at $\mathrm{t}=245.1^{\circ} \mathrm{C}, \mathrm{t}=300.6^{\circ} \mathrm{C}$ and $\mathrm{t}=303.0^{\circ} \mathrm{C}$ are peaks characteristic for the allocation of attached water bulk, at $\mathrm{t}=325.8^{\circ} \mathrm{C}$ and $\mathrm{t}=347.0^{\circ} \mathrm{C}$ are thermal effects, associated with polymorphic transformations of aluminum hydroxides, at $\mathrm{t}=401.20 \mathrm{C}$ is the peak typical for gibbsite $\left(\gamma-\mathrm{Al}(\mathrm{OH})_{3}\right)$, at $\mathrm{t}=493.0^{\circ} \mathrm{C}$ и $\mathrm{t}=50.5^{\circ} \mathrm{C}$ are exothermic effects, explained by oil burnout, at $\mathrm{t}=732.4^{\circ} \mathrm{C}$ and $\mathrm{t}=741.0^{\circ} \mathrm{C}$, the decomposition of carbonates occurs. Thermogravimetric curves (TG) show that all thermal effects are accompanied by a change in the mass of sediment samples depending on temperature. The increase in the residual mass of precipitation is explained by a change in their structure and properties.

The results of experimental studies on the cryogenic treatment of the oil emulsion wastewater sludge were carried out as follows: an equal volume $(97 \mathrm{ml})$ was poured into porcelain cups of different sediments with $S_{y d}^{0, w}=73 \mathrm{~mm} 2 / \mathrm{ml}$ (the same layer thickness) and the freezing depth (h) was fixed at certain time intervals: $\tau=0,30,60,90,120,150,180$ min. at various temperatures under natural conditions, the freezing depth (h) was determined at the same temperature, but with different wind speeds. Graphical dependences of the sediment freezing kinetics were constructed, based on the data obtained. Graphical dependencies were approximated using an Excel spreadsheet processor. Figures 4-6 show the graphic dependences of the sediment freezing kinetics at different values of oiliness and temperature. Figures 2-4 show the graphic dependences of the sediment freezing kinetics at different values of oiliness and temperature. 


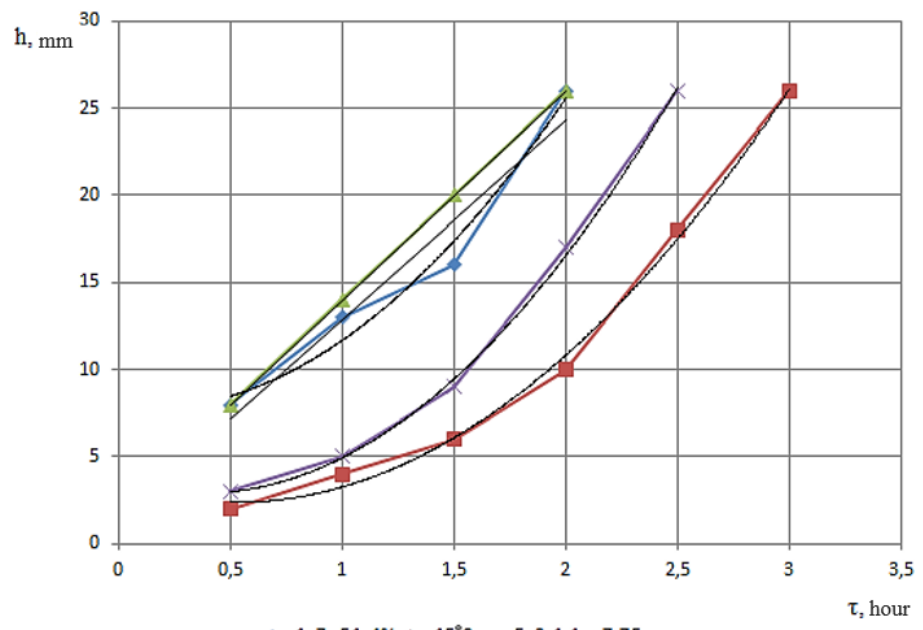

$\longrightarrow-1-\mathrm{Z}=51,4 \%, \mathrm{t}=-15^{\circ} \mathrm{C}-\mathrm{y}=5 \mathrm{x} 2-1,1 \mathrm{x}+7,75$

$-2-2-z=51,4 \%, t=-17^{\circ} \mathrm{C}-\mathrm{y}=5,1429 \times 2-3,8286 \mathrm{x}+3,6$

$-3-z=30,2 \%, t=-15^{\circ} \mathrm{C}-\mathrm{y}=12 \mathrm{x}+2$

$\longrightarrow 4-\mathrm{z}=30,2 \%, \mathrm{t}=-17^{\circ} \mathrm{C}-\mathrm{y}=3,8571 \times 2-4,0143 \mathrm{x}+3,4$

Fig. 2. Graphic dependences of the sediment freezing kinetics at different values of oil and temperature.

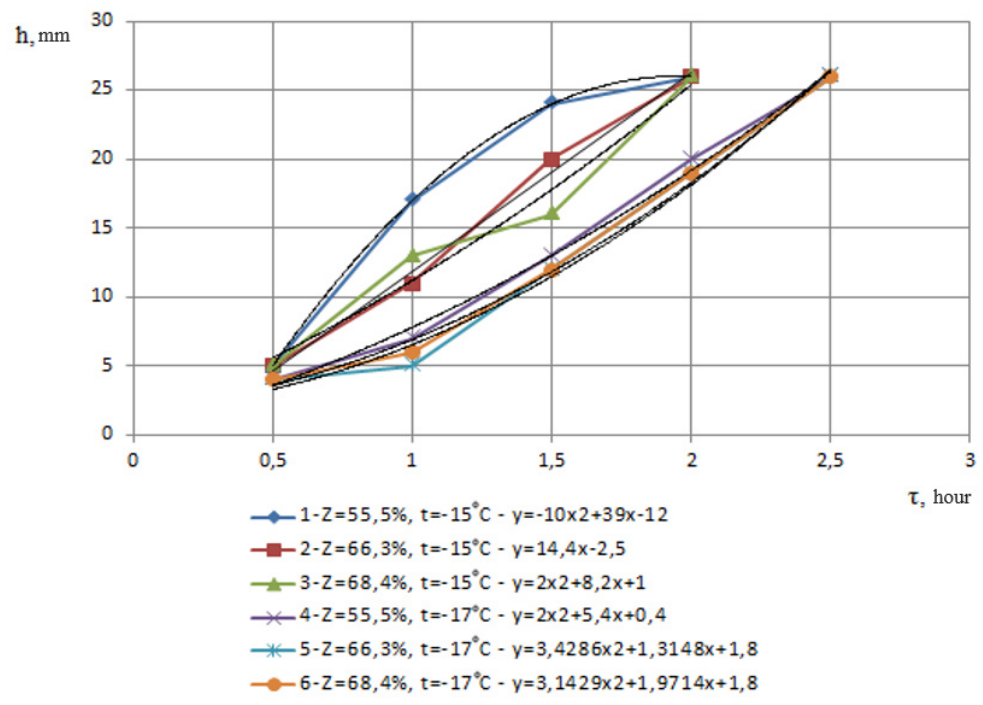

Fig.3. Graphic dependences of the sediment freezing kinetics at different values of oil and temperature. 


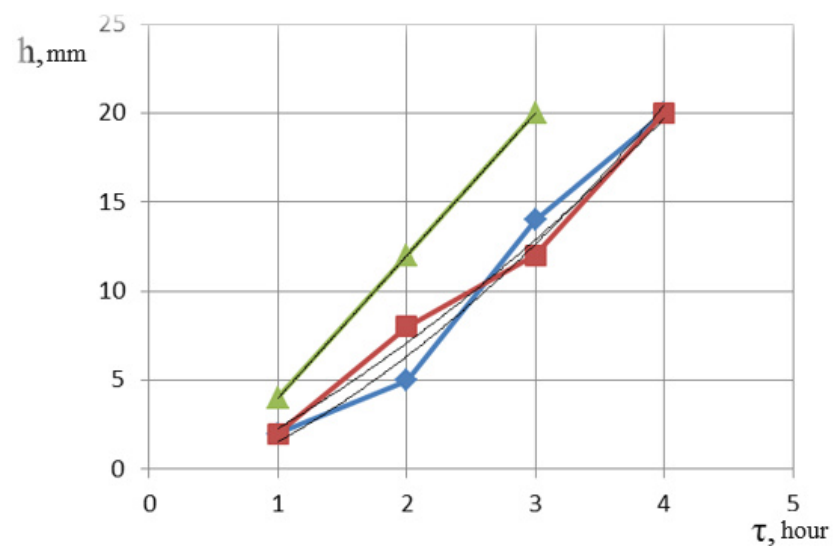

Fig.4. Graphic dependences of the sediment freezing kinetics at different temperatures and different wind speeds

The graphical dependences show the sediment freezing kinetics is affected by the oil content and cryogenesis conditions [4].

We gave an analytical assessment of the parameters of the sediment freezing process in our work. In order to process the experimental data, we used the problem solution of the sediment freezing, which surface interacted with outside air. The mathematical expression can be represented as the following equation:

$$
h=-h_{\tau}+\sqrt{h_{t}^{2}+2 \lambda\left(t_{c}-t_{a}\right) \frac{\tau}{L}},
$$

where $h_{t}=\frac{\lambda}{\alpha} ; \lambda$ - thermal conductivity coefficient, $\mathrm{W} / \mathrm{m} \cdot{ }^{\circ} \mathrm{C} ; \alpha-$ heat transfer coefficient; $\mathrm{L}$ - heat transfer coefficient $\mathrm{V} \mathrm{g} / \mathrm{m}^{3} ; \mathrm{t}_{\mathrm{c}}$ - sediment crystallization temperature, ${ }^{\circ} \mathrm{C} ; \mathrm{t}_{\mathrm{a}}$ - air temperature, ${ }^{\circ} \mathrm{C} ; \tau$ - freezing time, $\mathrm{h}$.

For the calculation we used the Taylor series:

$$
h(\tau)=\frac{A}{2 h_{\tau}} \cdot \tau-\frac{A^{2}}{8 h_{\tau}^{3}} \cdot \tau^{2}+\ldots
$$

where $A=\frac{2 \cdot \lambda \cdot\left(t_{c}-t a\right)}{L}$ is the first decomposition coefficient, which determines the linear part of thickness increase of the frozen layer and numerically equal to the angle slope of graphical dependence of the layer thickness on the freezing time. This allows determining its value with sufficient degree of accuracy. If we substitute the dependences of $\mathrm{A}$ and $\mathrm{h}_{\mathrm{t}}$ on the parameters in the expression of this coefficient the, we'll obtain:

$$
\frac{A}{2 h_{t}}=\frac{\alpha \cdot\left(t_{c}-t_{a}\right)}{L}
$$

We represent this coefficient, restricting to the first term in the expansion of the Taylor series, as an expression

$$
\frac{A}{2 \cdot h_{t}}=\frac{h(\tau)}{\tau},
$$

so, we can see that the coefficient has a dimension of speed and is determined by the ratio of the freezing layer thickness to the time of its cooling. The value of the freezing rate is determined by the heat transfer coefficient $\alpha$, the temperature difference $\left(t_{c}-t_{a}\right)$ and the heat of the phase transition L, based on this expression. It was experimentally established that 
the rate of oily sediment freezing is also affected by the oiliness $z$. The freezing rate can be calculated by the formula:

$$
\eta=(1-z) \cdot \frac{\alpha \cdot\left(t_{c}-t a\right)}{L}
$$

where z - oily sediment.

We studied the change in the properties of the oily sediment during freezing in vivo. The experimental data allowed us building the graphical dependencies, shown in Figures 58.

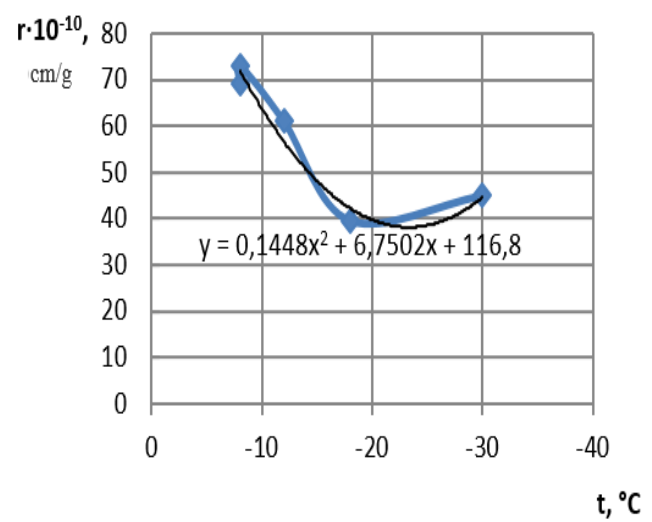

Fig. 5. Specific resistance dependence of sediment filtration on the freezing temperature.

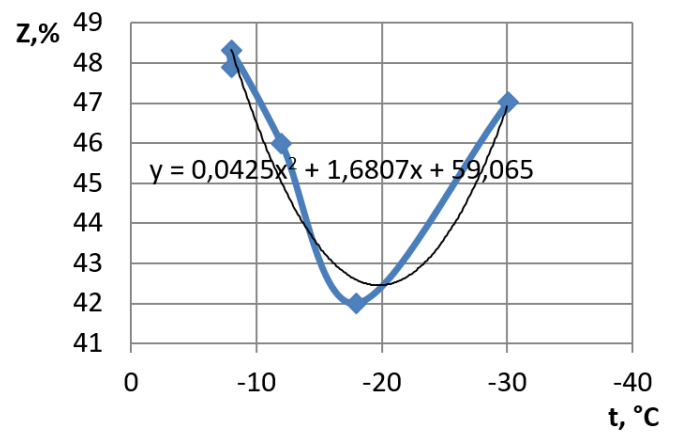

Fig. 6. Dependence of the change in the oil sediment content on the freezing temperature. 


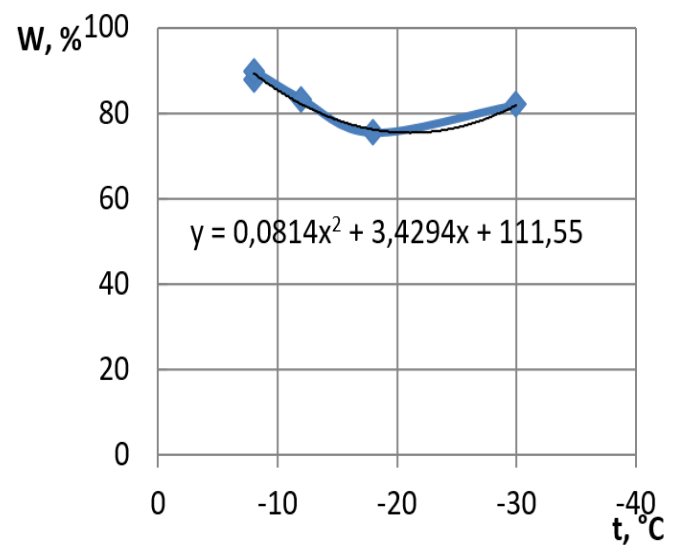

Fig. 7. Dependence of changes in sludge moisture on freezing temperature.

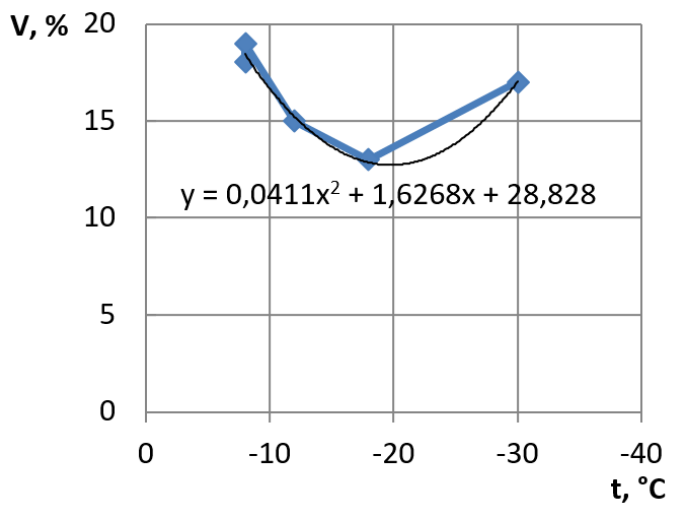

Fig. 8. Dependence of the change in sediment volume on temperature.

The graphical dependences show a decrease in temperature to a certain value $\left(-18^{\circ} \mathrm{C}\right)$ leads to a decrease in the water-discharge properties of the sediment, and a further decrease in temperature leads to an increase in these properties, or practically does not affect the process.

The authors proposed installations where it was possible to adjust the process of sediment freezing in the climatic conditions of Siberia $[4,5]$. We experimentally studied the influence on the slope of aileron angle on sediment loss. Data on changes in wind speed depending on the slope of aileron angle $\alpha$ are shown in figures 10-11

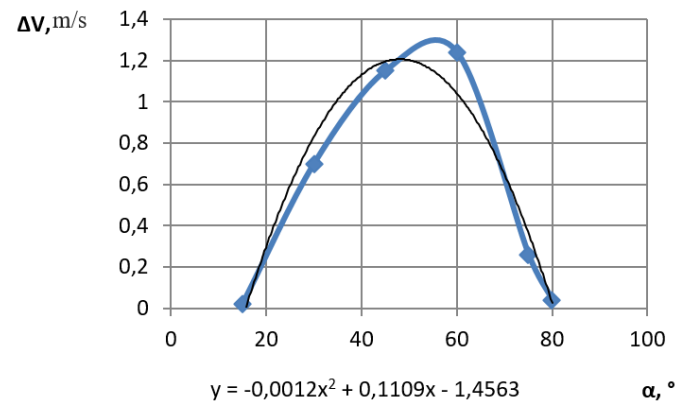

Fig. 9. Change in wind speed depending on the slope of aileron angle. 


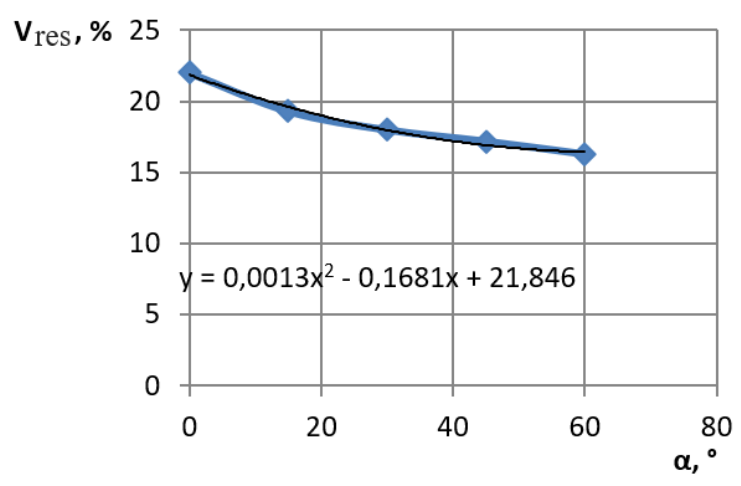

Fig. 10. Change in residual sediment volume depending on the slope of aileron angle.

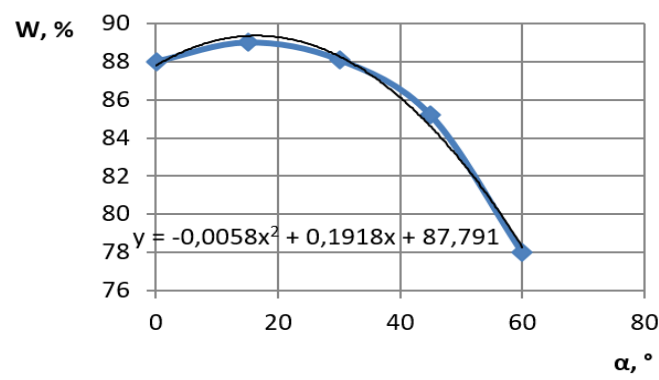

Fig. 11. Change in sediment moisture depending on the slope angle of the aileron

Figures 10-11 show the optimal slope angle of the aileron with the most intensive dewatering of the sediment is $\alpha=60^{\circ}$ [8].

It was proposed to equip the installation with a hollow traverse [4], which scheme is shown in Figure 12 in order to intensify the process of sludge dehydration and reduce the period of its complete freezing.

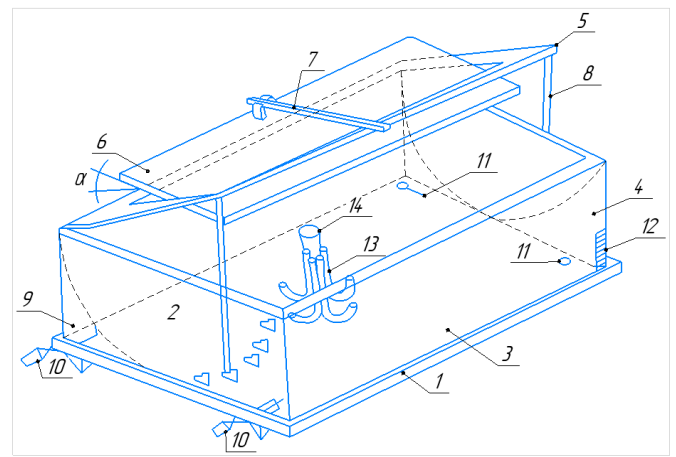

1 - mobile tank; 2 - a semi-cylindrical working chamber;

3 - side walls; 4 - hydraulic compartments; 5 - baffle; 6 - cavity, correcting the direction of air flow; 7 - system for raising the baffle; 8 - baffle installation system; 9 - end walls; 10, 11 - branch pipes supply and discharge of hot water; 12 - temperature sensor; 13 - traverse; 14 - mounting loop.

Fig. 12. Installation for sludge freezing.

The installation consists of a working chamber equipped with a baffle with mounted aileron plane, which can be installed at a certain angle of air flow; it allows changing the air speed above the cooling surface of the sediment and intensifying heat transfer and the 
freezing process kinetics [4].. The installation is also equipped with a mounting traverse of those branch pipes, which supply freezing process with cold air. The experimental data presented in table 2 .

Table 2. Sediment Freeze Test with the use of a traverse installation

\begin{tabular}{|c|c|c|c|c|c|c|c|}
\hline \multirow[b]{2}{*}{$\begin{array}{c}\text { Freezing } \\
\text { temperature }\end{array}$} & \multirow[b]{2}{*}{$\begin{array}{c}\text { Initial } \\
\text { sedimen } \\
\mathbf{t}\end{array}$} & \multicolumn{2}{|c|}{$-11^{\circ} \mathrm{C}$} & \multicolumn{2}{|c|}{$-16^{\circ} \mathrm{C}$} & \multicolumn{2}{|c|}{$-28^{\circ} \mathrm{C}$} \\
\hline & & $\begin{array}{l}\text { With } \\
\text { traverse }\end{array}$ & - & $\begin{array}{c}\text { With } \\
\text { travers } \\
\text { e }\end{array}$ & - & $\begin{array}{c}\text { With } \\
\text { traver } \\
\text { se }\end{array}$ & - \\
\hline Humidity\% & 98,9 & 76 & 85 & 72 & 75 & 79 & 83 \\
\hline Sediment volume, $\%$ & 100 & 12 & 15 & 10 & 13 & 12,5 & 17 \\
\hline $\begin{array}{c}\text { Sediment resistivity, } \\
10^{-10} \mathrm{sm} / \mathrm{g}\end{array}$ & 690 & 41 & 68 & 26 & 37 & 30 & 43 \\
\hline
\end{tabular}

The results of the experiment showed that optimal modes of sediment freezing are achieved using a hollow traverse. However, the conditions of freezing should be taken into account. The disadvantage of the installation for dewatering sludge [8] is the high complexity during maintenance. It was necessary to constantly monitor the information on the results achieved and to decide on manually changing the height of the rotation angle of the plane, which corrected the direction of air flow when the wind speed and temperature changed, which led to a long process of sewage sludge freezing.

It was proposed [6] additionally equip the installation with an automatic control system of the installation elements in order to increase efficiency, to reduce the complexity and the duration of the process, in the conditions of wind speed and temperature changing. The installation contains a plane angle sensor, having an error indicator and stabilizer angle adjuster switches, a plane altitude sensor with an error indicator, a wind speed sensor, a temperature sensor, a control unit, discrete hydraulic actuators associated with the actuators of the system for lifting and installing said plane

\section{Discussions}

It was found, that an increase in density, a decrease in humidity, resistivity of the sludge, filtration, oiliness and volume of sludge occurred, which were explained by a change in the structure due to the redistribution of various forms of moisture bond with the sediment particles during freezing of an oil-containing sludge and subsequent thawing.

It is shown that as the freezing temperature is lower and the wind speed is higher, then, the dehydration process intensity is greater. However, a lesser effect of dehydration is observed at low temperatures $\left(-30^{\circ} \mathrm{C}\right)$ with an increase in the freezing intensity and wind speeds, since the rate of solid particles displacement and oil particles within hydroxide bonds deformation becomes comparable with the freezing rate. The research data showed, that the plant's equipment with an aileron plane made it possible to intensify the velocity field, which affected the surface density of the heat flux, it determined the completeness of sludge freezing and caused dehydration.

The results of the experiment showed, that optimal modes of sediment freezing were achieved, using a hollow traverse, however, the conditions of freezing should be taken into account. We proposed to equip the installation additionally with an automatic control system for its elements in order to reduce the complexity, the duration of the process and to increase the installation efficiency, in a condition of the wind speed and temperature changed.

The control of the freezing sewage sludge process is ensured with the use of an automatic control system. The correcting direction of air flow in a condition of the wind speed and temperature change is achieved without staff's direct management of the 
sediment freezing process, which leads to lower its operating costs. The use of an automatic control system provides control over the process of freezing sewage sludge.

\section{Conclusions}

1. Experimental studies of properties, composition and structure of the natural sludge of oil emulsion wastewater after its freezing and thawing, using $\mathrm{x}$-ray phase and thermogravimetric analysis were carried out. It was established that the precipitate was in an amorphous state, characterized by high humidity and a high value of specific filtration resistance. The structure of the precipitate changed after freezing, due to the redistribution of moisture bond forms with the particles of the precipitate, which led to an improvement in water discharge properties.

2. The cryogenesis process was studied and an analytical assessment of kinetics parameters of the sediment freezing process was given. It was shown that the value of the freezing rate was determined by the heat transfer coefficient $\alpha$, the temperature difference (tc ta), heat of the phase transition $L$, and amount of oiliness - $\mathrm{z}$ of the sediment.

3. The oil-containing sludge properties in the freezing process under natural conditions were determined and graphical dependencies were constructed, so lowering the temperature to a certain value $\left(-18^{\circ} \mathrm{C}\right)$ reduced the water-giving properties of the sludge, and further lowering the temperature worsened water loss or practically did not affect the process.

4. It was shown that optimal modes of sediment freezing were achieved using ailerons and hollow traverses, however, the conditions of freezing should be taken into account.

5. It was proposed to equip the installation additionally with an automatic control system for its elements in order to reduce the complexity, the duration of the process and to increase the installation efficiency, in a condition of the wind speed and temperature changed.

\section{References}

1. A.M. Blagorazumova, Treatment and dewatering of urban wastewater sludge (2014)

2. V.M. Lyubarsky, Influence of freezing of sewage sludge on the intensification of their dehydration (2001)

3. V.P. Ivanova, Nedra (2003)

4. T.I. Halturin, A.C. Klimov and O. Klimov, RF patent 132067 (2013)

5. T.I. Khalturina and O.B. Churbakova. Construction 11-12. 84-89 (2012)

6. B.F. Turutin, T.I. Khalturina, T.I. Pazenko and E.A. Kotanova, USSR copyright certificate (2000) 